\title{
HUBUNGAN ANTARA BODY IMAGE DAN PERILAKU MAKAN DENGAN STATUS GIZI REMAJA PUTRI DI SMA THERESIANA SEMARANG
}

\author{
Nur Widianti, Aryu Candra $\mathbf{K}^{*}$ \\ Program Studi Ilmu Gizi Fakultas Kedokteran Universitas Diponegoro \\ Jl.Dr.Sutomo No.14, Semarang, Telp (024) 8453708, Email : gizifk@undip.ac.id
}

\begin{abstract}
Background: The dissatisfaction with their body shapes is commonly found among female adolescents. The lack of the contentment lead them to gain an ideal body shape but, unfortunately, they implement improper eating behaviour. The extreme diet they have affects negatively to their nutritional status. This study was aimed at analyzing the association between the body image and eating behaviour with nutritional status of female adolescents.

Methods: The study was cross-sectional on 72 female students of grade X, XI and XII in Theresiana Senior High School Semarang. The samples were taken based on simple random sampling. The samples were fulfilled inclusive criterion. The data were gathered by using questionnaires and focus group discussion (FGD). The FGD was intended to find more data on body image. Nutritional status data was obtained by measuring weight and height. Then, z-score was calculated based on BMI/ U by using WHO Anthro Plus 2007.

Results: A total of 29 subjects (40.3\%) were not satisfied with their body shape and 43 subjects (59.7\%) were satisfied with their body shape. The majority (56.9\%) subjects have not good eating behavior yet, whereas $43.1 \%$ of them have good eating behavior. There were significant association between body image with nutritional status $(r=$ $0.482 p=0.001)$ and eating behavior with nutritional status $(r=0.507 p=0.001)$.

Conclusion: Body image and the eating behavior were associated with nutritional status of female adolescents.
\end{abstract}

Key words: Body image; eating behavior; nutritional status; female adolescents

\begin{abstract}
ABSTRAK
Latar Belakang : Ketidakpuasan terhadap bentuk tubuh semakin sering dijumpai pada remaja putri. Hal ini membuat remaja putri menerapkan perilaku yang tidak tepat dalam mencapai tubuh ideal dengan melakukan diet yang terlalu ketat, sehingga akan berdampak negatif pada status gizi. Penelitian ini bertujuan untuk menganalisis hubungan antara body image dan perilaku makan dengan status gizi remaja putri.

Metode: Studi cross-sectional pada 72 siswi kelas X, XI, dan XII SMA Theresiana Semarang. Pemilihan sampel dengan menggunakan simple random sampling yang memenuhi kriteria inklusi. Data body image dan perilaku makan diperoleh dengan menggunakan kuesioner. Data status gizi diperoleh dari pengukuran TB dan BB, selanjutnya dihitung nilai z-score berdasarkan BMI/U menggunakan program WHO Anthro Plus 2007.

Hasil: Sebanyak 29 subyek (40.3\%) merasa tidak puas tehadap bentuk tubuhnya dan 43 subyek (59.7\%) merasa puas terhadap bentuk tubuhnya. Sebagian besar (56.9\%) subyek belum menjalankan perilaku makan yang baik dan 31 subyek (43.1\%) sudah menjalankan perilaku makan yang baik. Terdapat hubungan yang bermakna antara body image dengan status gizi $(r=0.482 p=0.001)$ dan perilaku makan dengan status gizi $(r=0.507 p=0.001)$

Simpulan: Ada hubungan antara body image dan perilaku makan dengan status gizi remaja putri.
\end{abstract}

Kata Kunci: Body image; perilaku makan; status gizi; remaja putri

\section{PENDAHULUAN}

Periode remaja adalah periode transisi dari anak - anak menuju dewasa, yang berawal pada usia 9 - 10 tahun dan berakhir pada usia 18 tahun. ${ }^{1}$ Pada masa ini, remaja sebagai seorang individu yang sedang mengalami perkembangan secara psikologis dan terjadinya perubahan fisik yang sangat cepat. ${ }^{2}$ Perubahan fisik ini akan membuat remaja mulai menyibukkan dirinya untuk lebih memperhatikan bentuk tubuh, khususnya terjadi pada remaja putri. ${ }^{3}$ Kebiasaan makan sehari-hari sangat berpengaruh terhadap pencapaian tubuh yang ideal, misalnya saja pembatasan asupan makanan agar berat badan tidak berlebih. ${ }^{4}$

Banyak remaja yang merasa tidak puas dengan penampilan dirinya sendiri, apalagi yang menyangkut tentang body image atau persepsi terhadap tubuhnya. ${ }^{4}$ Bentuk tubuh tinggi dan langsing merupakan hal yang diinginkan oleh remaja putri. Pada kenyataannya, banyak remaja putri yang merasa tidak puas terhadap bentuk tubuhnya karena ketidaksesuaian ukuran tubuhnya 
dengan ukuran tubuh yang diinginkan. Penelitian yang dilakukan Tarigan di Yogyakarta menunjukan hasil bahwa $67 \%$ remaja obesitas dan $33 \%$ remaja yang tidak obesitas menyatakan ketidakpuasan terhadap body image. ${ }^{5}$

Sebagian besar remaja putri menginginkan tubuhnya lebih tinggi dan langsing dengan melakukan perubahan perilaku makan. ${ }^{6}$ Hal ini terkadang membawa pengaruh yang buruk, sehingga remaja akan menerapkan perilaku tidak tepat dalam mencapai bentuk tubuh yang ideal dengan melakukan diet yang terlalu ketat. Praktek diet yang ketat pada remaja akan meningkatkan risiko status gizi buruk dan eating disorder, yaitu berupa anorexia nervosa atau bulimia nervosa. ${ }^{4}$ Penelitian tahun 2010 di SMA Negeri 4 Semarang menunjukkan bahwa sebagian besar $(87,1 \%)$ remaja putri belum menjalankan perilaku makan yang baik, dan hanya $12,9 \%$ remaja putri yang sudah menjalankan perilaku makan yang baik. ${ }^{7}$ Kebiasaan makan yang tidak sehat akan menimbulkan berbagai macam masalah gizi pada remaja, contohnya adalah tubuh yang terlalu kurus. $^{8}$

Keadaan status gizi remaja pada umumnya dipengaruhi oleh kebiasaan makan. ${ }^{9}$ Kekurangan gizi pada remaja sering terjadi akibat pembatasan konsumsi makanan dengan tidak memperhatikan kaidah gizi dan kesehatan. ${ }^{6}$ Mereka yang tidak puas terhadap bentuk tubuhnya akan melakukan pembatasan terhadap konsumsi makanannya, bahkan melakukan diet yang ketat tanpa nasehat atau pengawasan dari seorang ahli gizi atau ahli kesehatan. Akibatnya, asupan gizi secara kuantitas dan kualitas tidak sesuai dengan Angka Kecukupan Gizi (AKG) yang dianjurkan. ${ }^{6}$

Pembatasan konsumsi jenis makanan tertentu atau mempunyai kebiasaan diet tidak terkontrol dengan tujuan untuk mendapatkan tubuh yang ideal (langsing) sering terjadi pada remaja putri, khususnya siswi SMA (Sekolah Menengah Atas). ${ }^{10}$ SMA Theresiana Semarang adalah SMA swasta yang terletak di pusat kota Semarang, sehingga akses terhadap media massa sangat tinggi. Berdasarkan latar belakang di atas, maka penelitian ini akan menganalisis hubungan antara body image dan perilaku makan dengan status gizi pada remaja putri di SMA Theresiana Semarang.

\section{METODE}

Penelitian ini merupakan penelitian observasional dengan rancangan cross sectional dan termasuk dalam lingkup keilmuan gizi masyarakat. Penelitian dilakukan di SMA
Theresiana Semarang pada bulan Agustus 2012. Populasi dalam penelitian adalah siswi kelas X, XI dan XII di SMA Theresiana Semarang. Berdasarkan perhitungan menggunakan rumus estimasi proporsi didapatkan subjek minimal adalah 65 subjek dan dalam penelitian ini diperoleh 72 subjek. Metode pengambilan sampel dengan menggunakan simple random sampling, yang sebelumnya telah dipilih sesuai dengan kriteria inklusi yakni tidak sakit atau absen selama proses pengambilan data serta tidak sedang menjalani diet karena penyakit tertentu.

Data yang dikumpulkan dalam penelitian adalah identitas sampel, status gizi (variabel terikat), body image (variabel bebas), dan perilaku makan (variabel bebas). Status gizi adalah gambaran keadaan gizi seseorang yang ditentukan berdasarkan perhitungan IMT kemudian dikonversikan ke dalam nilai z-score BMI/U untuk anak perempuan usia 5-19 tahun menggunakan program WHO Anthro Plus 2007. Status gizi dikategorikan menjadi obesitas $>+2 \mathrm{SD}$, overweight $>+1$ SD, normal $-2 \mathrm{SD}-+1 \mathrm{SD}$, kurus <-2SD dan sangat kurus <-3SD. ${ }^{11}$ Berat badan ditimbang dengan timbangan digital yang memiliki kapasitas $150 \mathrm{~kg}$ dan ketelitian $0,1 \mathrm{~kg}$, sedangkan tinggi badan diukur dengan microtoise yang memiliki kapasitas $200 \mathrm{~cm}$ dan ketelitian $0,1 \mathrm{~cm}$.

Body image diukur dengan menggunakan kuesioner Body Shape Questionnaire (BSQ) yang berisi 34 pertanyaan dengan rentang skala 1 (tidak pernah) sampai 6 (selalu). Hasil skor body image kemudian diinterpretasikan dalam 2 kategori, yaitu puas terhadap bentuk tubuh (skor $\leq 110)$ dan tidak puas terhadap bentuk tubuh (skor $>110)^{12}$ Kemudian dilakukan FGD (focus group discussion) dipilih secara random kepada 10 subyek yang merasa tidak puas dengan bentuk tubuhnya untuk menggali lebih dalam mengenai body image.

Perilaku makan merupakan respon kebiasaan atau upaya-upaya yang dilakukan remaja berkaitan dengan konsumsi makan sehari-hari. Perilaku makan diukur dengan menggunakan kuesioner yang berisi 15 pertanyaan. Hasil ukur perilaku makan remaja diperoleh melalui skala model Likert dengan cut off point berdasarkan nilai ratarata skor-T, yaitu sudah menjalankan perilaku makan yang baik $\{\geq$ mean skor-T (50) $\}$ dan belum menjalankan perilaku makan yang baik $\{<$ mean skor-T (50) $\}^{13}$

Kuesioner yang digunakan pada penelitian ini telah diujicoba di lapangan dan dilakukan uji validitas dan reliabilitasnya dengan Alpha 
Cronbach sebesar 0,792 (kuesioner perilaku makan) dan 0,959 (kuesioner body image). Analisis data menggunakan program Statistic Package For The Social Science (SPSS). Analisis univariat dilakukan untuk mendeskripsikan setiap variabel penelitian meliputi nilai minimum dan maksimum, nilai rata-rata, dan standar deviasi dengan tabel distribusi frekuensi pada usia subjek, status gizi, body image, dan perilaku makan. Sebelum uji hipotesis, dilakukan uji kenormalan dengan Kolmogorov Smirnov yang kemudian dilanjutkan dengan analisis bivariat yaitu menghubungkan antara body image dengan status gizi dan perilaku makan dengan status gizi menggunakan uji korelasi $r$ Pearson. ${ }^{14}$

\section{HASIL PENELITIAN}

\section{A. Karakteristik Subyek}

\section{Usia}

Usia subjek dalam penelitian berkisar antara 15-18 tahun. Subyek dengan usia 15 tahun sebanyak 22 subyek (30,6\%), usia 16 tahun sebanyak 23 subyek $(31,9 \%)$, frekuensi terbesar yaitu usia 17 tahun sebanyak 24 subjek (33.3\%) sedangkan frekuensi terkecil yaitu usia 18 tahun sebanyak 3 subyek $(4,2 \%)$.

\section{Status Gizi}

Dari hasil pengukuran berat badan didapatkan bahwa rata - rata subyek memiliki berat badan $55,22 \mathrm{~kg}$ dengan nilai tertinggi $82,7 \mathrm{~kg}$ dan nilai terendah $36,9 \mathrm{~kg}$. Rata - rata tinggi badan subyek adalah $155,9 \mathrm{~cm}$ dengan nilai tertinggi $170,5 \mathrm{~cm}$ dan nilai terendah $139,5 \mathrm{~cm}$. Hasil pengukuran status gizi subjek menunjukkan rata-rata BMI sebesar 22.7 $\mathrm{kg} / \mathrm{m} 2$. Nilai BMI terendah yaitu $15 \mathrm{~kg} / \mathrm{m} 2$ sedangkan BMI tertinggi $36.8 \mathrm{~kg} / \mathrm{m} 2$. Kategori status gizi diperoleh berdasarkan nilai z-score BMI menurut usia 5-19 tahun. Berdasarkan hasil pengukuran diperoleh bahwa sebagian besar subjek mempunyai status gizi normal sebanyak 43 subjek $(59.7 \%)$.

\section{Body Image}

Berdasarkan hasil pengukuran body image melalui Body Shape Questionnaire (BSQ) diperoleh hasil bahwa sebanyak 43 subyek $(59.7 \%)$ puas terhadap bentuk tubuh dan sebanyak 29 subyek (40.3\%) tidak puas tehadap bentuk tubuh.

$$
\begin{array}{ccr}
\text { Setelah dilakukan } & \text { pengukuran } \\
\text { menggunakan } & \text { kuesioner, } & \text { kemudian }
\end{array}
$$

dilakukan focus group discussion (FGD) dengan 10 subyek yang memiliki ketidakpuasan terhadap bentuk tubuh. Subyek terdiri dari 5 remaja putri dengan status gizi normal dan 5 remaja putri dengan status gizi berlebih (obesitas dan overweight). Kelompok subyek dengan status gizi normal mengungkapkan alasan ketidakpuasan terhadap bentuk tubuh yaitu karena mereka menganggap tubuh mereka terlalu gemuk dan tidak proporsional. Sebanyak 3 subyek merasa tidak puas dengan tubuhnya karena merasa terlalu gemuk. Dua subyek lainnya berpendapat bahwa terdapat beberapa bagian tubuh mereka (misalnya lengan, paha) terlalu besar dan tidak sesuai dengan ukuran tubuh mereka. Hal tersebut membuat mereka berusaha menurunkan berat badannya. Metode yang digunakan yaitu dengan cara mengurangi porsi makan dan melakukan olah raga seperti senam. Terdapat 4 subyek yang mengaku tidak percaya diri atas bentuk tubuhnya, namun 1 subyek lainnya mengaku percaya diri atas bentuk tubuhnya.

Kelompok subyek dengan status gizi lebih (obesitas dan overweight) mengungkapkan alasan ketidakpuasan yaitu dikarenakan tubuh mereka terlalu besar. Kelima subyek mengaku tidak nyaman dengan ukuran tubuh mereka yang terlalu besar sehingga menimbulkan rasa tidak percaya diri. Akibat ketidakpuasan terhadap bentuk tubuhnya, mereka juga melakukan berbagai cara untuk menurunkan berat badannya, seperti mengurangi porsi makan, melakukan olah raga, bahkan terdapat 2 subyek mengaku mengkonsumsi obat pelangsing. Kedua kelompok subyek berpendapat bahwa tubuh yang ideal adalah tubuh yang tinggi, langsing, seluruh bagian tubuh proporsional dan tidak ada salah satu bagian tubuh yang terlihat terlalu menonjol.

\section{Perilaku Makan}

Berdasarkan hasil pengukuran perilaku makan melalui kuesioner diperoleh hasil bahwa sebanyak 41 subyek (56.9\%) belum menjalankan perilaku makan yang baik dan sebanyak 31 subyek $(43.1 \%)$ sudah menjalankan perilaku makan yang baik. 
Tabel.1 Distribusi Frekuensi Usia, Status Gizi, Body Image, dan Perilaku Makan

\begin{tabular}{|c|c|c|}
\hline Variabel & $\begin{array}{c}\text { Frekuensi } \\
\mathbf{N}\end{array}$ & Persen \\
\hline \multicolumn{3}{|l|}{ Usia (tahun) } \\
\hline 15 & 22 & 30.6 \\
\hline 16 & 23 & 31.9 \\
\hline 17 & 24 & 33.3 \\
\hline 18 & 3 & 4.2 \\
\hline Total & 72 & 100.0 \\
\hline \multicolumn{3}{|l|}{ Status Gizi } \\
\hline Obesitas (> + 2 SD) & 10 & 13.9 \\
\hline Overweight (> + 1 SD) & 17 & 23.6 \\
\hline Normal (-2 SD - +1 SD) & 43 & 59.7 \\
\hline Kurus $(<-2 S D)$ & 2 & 2.8 \\
\hline Sangat kurus $(<-3 \mathrm{SD})$ & 0 & 0 \\
\hline Total & 72 & 100.0 \\
\hline \multicolumn{3}{|l|}{ Body Image } \\
\hline Puas $($ skor $\leq 110)$ & 43 & 59.7 \\
\hline Tidak puas (skor > 110 ) & 29 & 40.3 \\
\hline Total & 72 & 100 \\
\hline \multicolumn{3}{|l|}{ Perilaku Makan } \\
\hline $\begin{array}{l}\text { Sudah menjalankan } \\
\text { perilaku makan yang } \\
\text { baik } \\
\{\geq \text { mean skor-T }(\geq 50)\}\end{array}$ & 31 & 43.1 \\
\hline $\begin{array}{l}\text { Belum menjalankan } \\
\text { perilaku makan yang } \\
\text { baik } \\
\{<\text { mean skor-T }(<50)\}\end{array}$ & 41 & 56.9 \\
\hline Total & 72 & 100 \\
\hline
\end{tabular}

B. Tabulasi Silang antara Body Image dan Perilaku Makan dengan Status Gizi

Tabel 2. Tabulasi Silang antara Body Image dengan Status Gizi

\begin{tabular}{lcccccc}
\hline \multirow{2}{*}{ Status Gizi } & \multicolumn{4}{c}{ Body Image } & \multicolumn{3}{c}{ Total } \\
\cline { 2 - 6 } & \multicolumn{2}{c}{ Puas } & \multicolumn{2}{c}{ Tidak Puas } & & \\
\cline { 2 - 6 } & $\mathrm{n}$ & $\%$ & $\mathrm{~N}$ & $\%$ & $\mathrm{n}$ & $\%$ \\
\hline Obesitas & 0 & 0 & 10 & 13.9 & 10 & 13.9 \\
Overweight & 7 & 9.8 & 10 & 13.9 & 17 & 23.6 \\
Normal & 34 & 47.2 & 9 & 12.5 & 43 & 59.8 \\
Kurus & 2 & 2.7 & 0 & 0 & 2 & 2.7 \\
\hline Total & $\mathbf{4 4}$ & $\mathbf{5 9 . 7}$ & $\mathbf{2 9}$ & $\mathbf{4 0 . 3}$ & $\mathbf{7 2}$ & $\mathbf{1 0 0}$ \\
\hline
\end{tabular}

Berdasarkan tabel 2, menunjukkan hasil bahwa dari 29 subjek (40.3\%) yang mengalami ketidakpuasan terhadap bentuk tubuh tidak hanya terjadi pada subjek dengan kelebihan berat badan saja, namun juga pada subjek dengan status gizi normal yaitu sebanyak 9 subjek (12.5\%). 
Tabel.3 Tabulasi Silang antara Perilaku Makan dengan Status Gizi

\begin{tabular}{ccccccc}
\hline Status Gizi & \multicolumn{4}{c}{ Perilaku Makan } & \multicolumn{2}{c}{ Total } \\
\cline { 2 - 6 } & $\begin{array}{c}\text { Sudah menjalankan } \\
\text { perilaku makan yang } \\
\text { baik }\end{array}$ & $\begin{array}{c}\text { Belum menjalankan } \\
\text { perilaku makan yang } \\
\text { baik }\end{array}$ & \multicolumn{2}{c}{ n } & $\%$ \\
\cline { 2 - 6 } Obesitas & 1 & 1,4 & 9 & 12.5 & 10 & 13.9 \\
Overweight & 2 & 2.8 & 15 & 20.8 & 17 & 23.6 \\
Normal & 27 & 37.5 & 16 & 22.2 & 43 & 59.7 \\
Kurus & 1 & 1.4 & 1 & 1.4 & 2 & 2.8 \\
\hline Total & $\mathbf{3 1}$ & $\mathbf{4 3 . 1}$ & $\mathbf{4 1}$ & $\mathbf{5 6 . 9}$ & $\mathbf{7 2}$ & $\mathbf{1 0 0}$ \\
\hline
\end{tabular}

Berdasarkan tabel 3, menunjukkan bahwa subyek yang belum menjalankan perilaku makan yang baik dengan status gizi overweight yaitu sebanyak $20,8 \%$. Terdapat pula subyek dengan status gizi normal yang belum menjalankan perilaku makan yang baik yaitu sebanyak 22, $2 \%$.

C. Analisis Bivariat

Analisis hubungan antara variabel bebas dengan variabel terikat terlebih dahulu dilakukan uji kenormalan data dengan Kolmogorov Smirnov. Variabel bebas perilaku makan dan body image adalah berdistribusi normal dan variable terikat status gizi juga berdistribusi normal sehingga digunakan uji korelasi $r$ Pearson.

1. Hubungan body image dengan status gizi
Berdasarkan hasil analisis bivariat antara body image dengan status gizi menunjukkan adanya korelasi yang bermakna ( $\mathrm{r}=0,482 p=0,001)$. Hal ini berarti semakin tinggi ketidakpuasan terhadap body image, maka status gizinya semakin tidak normal (obesitas atau overweight).

2. Hubungan perilaku makan dengan status gizi

Analisis bivariat antara perilaku makan dengan status gizi menunjukkan adanya korelasi yang bermakna $(r=0,507$ $p=0,001)$. Hal ini berarti semakin baik subyek menjalankan perilaku makan, maka status gizinya semakin baik.

Tabel 6. Analisis bivariat body image dan perilaku makan dengan status gizi

\begin{tabular}{lcc}
\hline \multirow{2}{*}{ Variabel Bebas } & \multicolumn{3}{c}{ Variabel Terikat } \\
Status Gizi
\end{tabular}

\section{PEMBAHASAN}

Subyek dalam penelitian ini berusia 15-18 tahun, dengan frekuensi terbesar yaitu usia 17 tahun yaitu sebanyak 24 subjek (33.3\%). Pada rentang usia tersebut, subyek termasuk dalam tahap remaja menengah (middle adolescence) dimana penampilan menjadi faktor penting bagi remaja, sehingga mereka berusaha untuk meningkatkan perhatian terhadap bentuk tubuhnya dengan melakukan sesuatu agar penampilan fisiknya terlihat lebih baik. ${ }^{15}$ Hal ini didukung oleh hasil penelitian oleh Sivert dan Sinanovic yang menyatakan bahwa ketidakpuasan terhadap bentuk tubuh lebih sering terjadi pada remaja, khususnya remaja putri, dibandingkan wanita dewasa. Hal tersebut dikarenakan remaja lebih mudah dipengaruhi oleh media dan tren saat ini. ${ }^{16}$

Ketidakpuasan body image pada remaja putri terjadi karena ketidaksesuaian bentuk tubuhya dengan bentuk tubuh yang diinginkan. Masa pubertas pada remaja putri dibarengi dengan peningkatan lemak tubuh. Akibat adanya 
perubahan komposisi tubuh menyebabkan remaja sering merasa tidak puas dengan bentuk tubuhnya. ${ }^{17}$

Berdasarkan hasil pengukuran body image melalui Body Shape Questionnaire (BSQ) diketahui bahwa sebanyak 43 subyek (59.7\%) puas terhadap bentuk tubunya dan sebanyak 29 subyek $(40.3 \%)$ merasa tidak puas tehadap bentuk tubuhnya. Ditemukan pula 9 subyek $(12,5 \%)$ dengan status gizi normal namun merasa tidak puas dengan bentuk tubuhnya. Hasil tersebut sejalan dengan penelitian yang dilakukan oleh Kusumajaya yang menyatakan bahwa terdapat $12 \%$ remaja yang merasa gemuk padahal status gizinya normal. ${ }^{6}$ Hal ini memperlihatkan bahwa meskipun subjek telah mempunyai tubuh ideal namun mereka cenderung menilai ukuran tubuhnya lebih besar dari ukuran sebenarnya. ${ }^{17}$ Hal tersebut juga diperkuat dengan hasil dari foccus group discussion (FGD) dengan subyek yang memiliki status gizi normal namun tidak puas terhadap bentuk tubuhnya. Ketidakpuasan tersebut dikarenakan subyek merasa tubuhnya terlalu gemuk dan terdapat beberapa bagian tubuh (misalnya lengan, paha) yang tidak sesuai dengan ukuran tubuhnya sehingga terlihat tidak proporsional.

Hasil analisis bivariat menunjukkan bahwa body image berhubungan dengan status gizi dengan $\mathrm{r}=0,482, \mathrm{p}=0,000$. Hal tersebut mendukung penelitian yang dilakukan oleh Laus dkk di Brazil yang menyatakan bahwa terdapat hubungan anatara body image dengan status gizi ( $r$ $=0,37, p<001) \cdot{ }^{18}$ Ketidakpuasan terhadap bentuk tubuh pada remaja dengan menganggap tubuhnya terlalu gemuk membuat remaja melakukan upaya penurunan berat badan dengan cara yang salah, sehingga hal tersebut akan mempengaruhi status gizinya. $^{6}$

Sebagian besar remaja putri dalam penelitian ini belum menjalankan perilaku makan yang baik. Sebanyak 41 subyek $(56,9 \%)$ belum menjalankan perilaku makan yang baik dan 31 subyek $(43,1 \%)$ sudah menjalankan perilaku makan yang baik. Perilaku makan tidak baik yang dilakukan remaja dalam penelitian ini antara lain makan tidak teratur dan sering melewatkan waktu makan tertentu misalnya makan malam karena takut akan menjadi gemuk. Ketakutan akan menjadi gemuk menyebabkan remaja melewatkan waktu makan dan perilaku ini dianggap sebagai langkah awal untuk menurunkan berat badan. ${ }^{19}$ Selain makan malam, remaja juga sering melewatkan waktu makan pagi (sarapan). Tidak makan pagi justru dapat menyebabkan kegemukan. Hal tersebut dikarenakan rasa lapar akibat tidak makan pagi sehingga menyebabkan lebih banyak ngemil di siang hari, padahal cemilan memberikan kontribusi lemak yang cukup besar bagi tubuh. ${ }^{20}$

Analisis bivariat antara perilaku makan dengan status gizi menunjukkan adanya korelasi yang bermakna ( $r=0,507 p=0,001)$. Hasil tersebut sejalan dengan penelitian yang dilakukan oleh Gouado dkk di Kamerun yang menyatakan bahwa terdapat hubungan yang signifikan antara perilaku makan dengan status gizi $(p=0,006) \cdot{ }^{21}$ Sebagian besar remaja putri lebih memperhatikan berat badan dan bentuk tubuhnya dibandingkan dengan makanan. Hal ini berakibat pada pembatasan asupan makanan yang keliru. Pembatasan asupan makanan tersebut dikarenakan remaja merasa tubuhnya semakin gemuk sehingga mereka ingin memperbaiki penampilan fisiknya. ${ }^{10}$ Pembatasan konsumsi makanan dengan tidak memperhatikan kaidah gizi dan kesehatan untuk mendapatkan tubuh yang ideal (langsing), justru akan berdampak negatif pada status gizi remaja. ${ }^{6}$

\section{KETERBATASAN PENELITIAN}

Penelitian ini memiliki keterbatasan dalam hal pemilihan desain penelitian, sehingga hasil analisis kurang optimal.

\section{SIMPULAN}

Hasil penelitian ini menunjukkan bahwa terdapat hubungan yang bermakna antara body image dan perilaku makan dengan status gizi pada remaja putri. Semakin tinggi ketidakpuasan terhadap body image maka status gizinya semakin tidak normal (overweight atau obesitas). Ketidakpuasan terhadap body image rata-rata terjadi pada subyek dengan status gizi overweight dan obesitas. Terdapat pula subyek yang memiliki status gizi normal namun merasa tidak puas dengan bentuk tubuhnya. Ada hubungan antara perilaku makan dengan status gizi remaja. Semakin baik subyek menjalankan perilaku makan, maka status gizinya semakin baik.

\section{SARAN}

Bagi remaja putri yang memiliki ketidakpuasan terhadap bentuk tubuh perlu adanya bimbingan dan arahan dari pihak orang tua dan guru Bimbingan Konseling (BK), khususnya dalam hal perilaku makan sehingga tidak menimbulkan masalah gizi. Bagi remaja putri yang telah memiliki kepuasan terhadap bentuk tubuhnya agar dikembangkan dengan cara mengeksplorasi minat dan bakat yang 
dimiliki melalui kegiatan ekstrakurikuler sehingga dapat bermanfaat dalam perkembangan kepribadian yang positif.

Untuk penelitian lebih lanjut yang berkaitan dengan perilaku makan, disarankan untuk dilakukan secara langsung yaitu dengan mengobservasi perilaku makan responden serta menganalisis asupan makan secara kuantitatif.

\section{DAFTAR PUSTAKA}

1. Arisman MB. Buku Ajar Ilmu Gizi, Gizi dalam Daur Kehidupan. Jakarta: Penerbit Buku Kedokteran EGC; 2004.hal.63:75-80.

2. Sarwono SW. Psikologi Remaja. Jakarta: PT.Raja Grafindo; 2010.hal:11-12.

3. Boschi V, Siervo M, D'Orsi P, Margiotta N, Trapanese E, Basile F, et al. Body Composition, Eating Behavior, Food-Body Concerns and Eating Disorders in Adolescent Girls. Ann Nutr Metab 2003;47:284-293

4. L. Kathlen Mahan, Sylvia Escott-Stump. Krause's Food, Nutrition and Diet Therapy. 12th edition. Philadelphia:Saunders; 2008.p:257.

5. Tarigan N. Hubungan Citra Tubuh dengan Status Obesitas, Aktifitas Fisik dan Asupan Energi Remaja di Kota Yogyakarta dan Kabupaten Bantul. Jurnal Ilmiah PANNMED Volume 2 Nomor 1; 2007.hal.3-8. Diunduh dari: http://isjd.pdii.lipi.go.id

6. Kusumajaya NA, Wiardani NK, dan Juniarsana IW. Persepsi Remaja terhadap Body Image Kaitannya dengan Pola Konsumsi Makan. Jurnal Skala Husada, Volume 5 Nomor 2; 2008.hal.114125. Diunduh dari: http://isjd.pdii.lipi.go.id

7. Setyorini K. Hubungan Body Image dan Pengetahuan Gizi dengan Perilaku Makan Remaja Putri. [Skripsi]. Program Studi Ilmu Gizi FK UNDIP; 2010.

8. Stevenson C, Doherty G, Barnett J, Muldon OT, and Trew K. Adolescents' Views of Food and Eating: Identifying Barriers to Healthy Eating. Journal of Adolescence. 2007; 30:417-434.

9. Thamrin MH, Kusharto CM, dan Setiawan B. Kebiasaan Makan dan Pengetahuan Reproduksi Remaja Putri. Jurnal Gizi dan Pangan; 2008.3:124131. Diunduh dari: http://isjd.pdii.lipi.go.id

10. Stang J and Story M. Understanding Adolescent Eating Behavior. Departement of Health and Human Services:US; 2005.p.1-15;101-102;155.

11. World Health Organization. Growth References 519 years for adolescence. Diunduh dari http://www.who.int//growthreferences5-

19yearsforadolescence 2007-pdf// pada tanggal 5 Mei 2012.

12. Di Pietro M. and Da Silveira XD. Internal Validity, Dimentionality and Performance of The Body Shape Questionnaire in A Group of Brazilian
College Student. Brazilia Journal Psychiatry; 2008.no.3.p.1-4.

13. Azwar S. Sikap Manusia Teori dan Pengukurannya. Yogyakarta: Pustaka Pelajar; 2009.hal.156.

14. Dahlan MS. Statistik untuk Kedokteran dan Kesehatan. Jakarta:Salemba Medika; 2008.hal.155;163.

15. Tarwoto, Aryani R, Nuraeni A, Miradwiyana B, Nurbayani S, dkk. Kesehatan Remaja Problem dan Solusinya. Jakarta:Salemba Medika; 2010.hal.2528.

16. Sivert, Selja Serifovic and Sinanovic, Osman. Body Dissatisfaction-Is Age A Factor. Journal Series Philosophy, Psychology, and History;2008.Vol.7. no.1. p55-61

17. Grogan S. Body Image, Understanding Dissatisfaction in Men, Women, and Children. New York: Routledge; 2008.p136-190.

18. Laus MF, Mota DC, Moreira RC, Costa TM, Almeida S. Physical Activity, Nutritional Status, and Body Image Concerns In Adolescents. Journal Brazailian Psiquatr;2009.Vol.58.no.3.p150-5.

19. Wan PL, Kandiah M, Taib MNM. Body Image Perception, Dietary Practices, and Physical Activity of Overweight and Normal Weight Malaysian Female Adolescents. Mal J Nutr. 2004; 10(2): 131-147

20. Matthys C, DeHaneuw S, Bellemans M, DeMaeyer M, DeBacker G. Breakfast Habits Affect Overall Nutrient Profiles in Adolescents. In : The Adolescents' Diet from a Public Health Perspective. 2006. p 53-69.

21. Gouado I, Tetanye E, Zolo PH. Nutritional Status, Food Habits and Energy Profile Of Young Adult Cameroonian University Students. African Journal of Food Science. 2010; Vol. 4(12).p.748 - 753. 